\title{
CARACTERIZAÇÃO FÍSICO-QUÍMICA E SENSORIAL DE VINHOS BRANCOS DA REGIÃO NOROESTE DE SÃO PAULO
}

\author{
M. B. M. Castilhos e V. L. Del Bianchi \\ Universidade Estadual Paulista "Júlio de Mesquita Filho" (UNESP), Instituto de Biociências, Letras e Ciências \\ Exatas, Campus São José do Rio Preto/SP \\ mbonattosp@yahoo.com.br - vanildo@ibilce.unesp.br
}

Artigo submetido em maio/2011 e aceito em setembro/2011

\section{RESUMO}

Os vinhos brasileiros são apreciados pelos consumidores por apresentar aroma e gosto frutado típico das cultivares Vitis labrusca. A rusticidade dessas cultivares, as etapas do processo de vinificação e as propriedades físico-químicas são alguns dos fatores para se obter uma bebida de qualidade. Nesse sentido, o objetivo desse artigo foi analisar físico-química e sensorialmente a qualidade de três vinhos brancos (dois brancos de mesa e um branco fino) de vinícolas da região noroeste do estado de São Paulo. Dados físicoquímicos e sensoriais foram analisados através de testes estatísticos e Análise de Componentes Principais (ACP). Observaram-se diferenças significativas $(P<0,05)$ nas determinações acidez total e fixa, extrato seco, teor de fenólicos totais e teor de açúcar redutor. Ademais, a ACP mostrou que os atributos corpo e cor explicaram os componentes 1 e 2, respectivamente, destacando-se o vinho fino para esses atributos. Assim, a relação entre as propriedades físico-químicas e sensoriais dos vinhos brancos estudados foi relevante para a caracterização dessas bebidas produzidas na região noroeste de São Paulo.

PALAVRAS-CHAVE: vinhos regionais, qualidade química, perfil sensorial, vinificação.

\section{PHYSICOCHEMICAL AND SENSORY CHARACTERIZATION OF WHITE WINES FROM NORTHWEST REGION OF SÃO PAULO}

\begin{abstract}
Brazilian wines are appreciated by consumers for having fruity odor and taste which are typical from Vitis labrusca cultivars. The rusticity of these cultivars, the winemaking and the physicochemical properties are some of the key factors to obtain a quality beverage. In this context, the aim of this article was to analyze the quality of three white wines from wineries located in northwest region of São Paulo state by determining physicochemical properties and sensory profile. Data were analyzed by statistical tests and by Principal
\end{abstract}

Component Analysis (PCA). It was possible to observe statistical differences $(P<0,05)$ in most physicochemical properties. Furthermore, the PCA showed that the attributes body and color significantly explained the variance of the first and second component, respectively, higlighting the Vitis vinifera wine. Thus the connection between the physicochemical and sensory properties of white wines was important for characterization of these beverages produced in the northwest of São Paulo.

KEY-WORDS: regional wines, chemical quality, sensory profile, vinification. 


\section{CARACTERIZAÇÃO FÍSICO-QUÍMICA E SENSORIAL DE VINHOS BRANCOS DA REGIÃO NOROESTE DE SÃO PAULO}

\section{INTRODUÇÃO}

Entende-se por vinho de mesa a bebida obtida pela fermentação alcoólica do mosto de uva sã, fresca e madura com teor alcoólico de $8,6 \%$ a $14 \%$ em volume podendo conter até uma atmosfera de pressão a $20^{\circ} \mathrm{C}$ (BRASIL, 2004). De acordo com Guerra (2003), o vinho de mesa e seus derivados são elaborados, no Brasil, com a utilização de uvas americanas e híbridas da espécie Vitis labrusca e representam mais de $80 \%$ da comercialização total em volume. Os estados brasileiros de destaque na produção desses vinhos são Minas Gerais, São Paulo, Paraná, Santa Catarina e Rio Grande do Sul, sendo esse responsável por cerca de $90 \%$ da produção (MELLO, 2002). O elaborado a partir dessas uvas propicia vinhos de características ímpares de gosto e aroma frutado muito apreciado pelos consumidores brasileiros.

O mercado do vinho, segundo a OIV (Organisation Internationale de La Vigne et du Vin), está centrado no continente europeu, sendo a França e a Itália os países responsáveis pela maior parte da produção mundial. O Brasil apresentou produção mundial de 2,50 milhões de hectolitros, evidenciando um decréscimo de $8,08 \%$ da produção de vinho no ano de 2010. Apesar desse panorama, o mercado brasileiro para o vinho de mesa pode ser considerado como promissor, pois os vinhos produzidos no Brasil apresentam um paladar suave e adocicado com o aroma muito próximo da uva. Outro fator que influencia diretamente na escolha do vinho de mesa está centrado no baixo poder aquisitivo da população, visto que o preço desse produto é mais acessível quando comparado aos vinhos nacionais especiais e finos (GUERRA, 2003). Conforme Mello (2002), outra característica é o fato desses produtos não possuírem concorrentes internacionais, já que os vinhos importados possuem outras técnicas de produção e utilizam uvas viníferas para a elaboração dos vinhos.

O gênero Vitis, ao qual pertence as videiras cultivadas ou selvagens, abrange cerca de 30 espécies, sendo que dentre elas as mais importantes são Vitis vinifera e outras de origem americana como Vitis labrusca, Vitis riparia, Vitis aestivalis, Vitis berlandieri, entre outras. As cultivares americanas e híbridas são geralmente utilizadas em áreas onde as condições ambientais não são muito favoráveis à viticultura como o Leste Norte-Americano, América Central, Brasil (maior parte) e outros países da América do Sul (AMARANTE, 1983). Nesse contexto, as regiões de clima tropical estão se destacando no cultivo de uvas rústicas e na produção de vinhos de mesa, visto que tais cultivares possibilitam programação da colheita para qualquer época do ano, eliminando períodos de entressafra e promovendo alta rentabilidade da cultura. Além disso, a produção dessas cultivares não exige estruturas diversificadas de grande apelo tecnológico, tradicional das grandes vinícolas gaúchas. Esses fatores são importantes para caracterizar o pioneirismo da região do vale do São Francisco - nordeste brasileiro - na produção de uvas como alternativa para a elaboração de vinhos de mesa regionais, estendendo-se para o norte do Paraná, noroeste de São Paulo e norte de Minas Gerais (CAMARGO, 2004).

A qualidade de um vinho de mesa está diretamente relacionada ao processo de vinificação, ou seja, a forma como a vindima foi realizada, tempo de fermentação e maceração, sulfitagem, aplicação de atestos e trasfegas e processos de clarificação e estabilização pelo frio (RIZZON, 2006; ROSIER, 1993). Essas etapas principais direcionam a qualidade química do vinho, isto é, o equilíbrio entre as 
substâncias químicas existentes no vinho como açúcares, álcoois e ésteres provenientes da uva e do processo de vinificação. A determinação das propriedades físico-químicas dos vinhos possibilita a visualização desse equilíbrio, identificando ou não a qualidade resultante do controle efetivo das etapas do processo de vinificação.

O álcool etílico apresenta a propriedade de tornar o meio impróprio para o desenvolvimento de microrganismos patogênicos. O teor alcoólico produzido durante o processo fermentativo está diretamente vinculado ao teor de açúcares fermentescíveis existentes na uva a ser vinificada. Esse teor de açúcares da matéria-prima depende basicamente de dois fatores: safra e variedade da uva, além de outros fatores como a aplicação do processo de chaptalização (MAZZOCHI; IDE, 1994). De acordo com a legislação brasileira, o teor alcoólico dos vinhos deve estar compreendido entre 8,6 e 14ํG, sendo permitida a prática de chaptalização - inserção de sacarose para a correção do teor alcoólico do mosto até 3GL (BRASIL, 2004).

Além do teor alcoólico, a acidez caracteriza-se por ser um parâmetro que indica o estado ótimo de fermentação, além de influenciar diretamente nas características sensoriais dos vinhos como a coloração (RIZZON; MIELE; MENEGUZZO, 1999). A acidez do vinho é dividida em duas frações: a acidez fixa, responsável pelos ácidos fixos como tartárico, málico, lático, succínico e cítrico (JACKSON, 2000) e a acidez volátil, representada pelos ácidos da série acética, além de ácidos graxos como o fórmico, butírico e propiônico (BARNABÉ, 2006). A sanidade do vinho está veiculada aos baixos teores de acidez volátil, indicando a ausência de ataques bacterianos que, porventura, possam promover a oxidação do álcool existente no meio ou a degradação do ácido cítrico, açúcares ou glicerol (ZOECKLEIN et al., 1994).

Os açúcares redutores apresentam-se como substâncias que não foram transformadas em álcool etílico pela ação das leveduras no processo fermentativo, sendo, em sua maioria, pentoses da classe das xiloses e arabinoses (AMERINE; OUGH, 1986). Esses açúcares são responsáveis pela doçura do vinho que, no caso de vinhos secos, não pode ultrapassar o limite de 5,0 g/L (BRASIL, 1999). Além dos açúcares redutores, o extrato seco total é uma das propriedades físico-químicas dos vinhos em geral que se relaciona com os compostos que são responsáveis pelo corpo e estruturação da bebida (RIZZON; MIELE, 1996). É obtido por meio do peso do resíduo seco após a evaporação dos compostos voláteis (BARNABÉ, 2006).

O corpo do vinho, além de estar relacionado ao extrato seco total, também apresenta influência de compostos fenólicos importantes como os taninos. Essas substâncias se complexam com as mucoproteínas existentes na saliva promovendo a sensação tátil bucal da adstringência (AMERINE; ROESSLER, 1983). Além dos taninos, existem outros compostos fenólicos que são responsáveis pela coloração de vinhos, as antocianinas. Porém, essas substâncias estão presentes em vinhos tintos, pois o processo de vinificação desses vinhos é realizado com a presença da casca da uva, local onde são encontrados esses pigmentos. No caso dos vinhos brancos, o processo de vinificação é realizado sem a presença das cascas e a cor amarelada típica desses vinhos é determinada pela oxidação de compostos fenólicos durante a fermentação e envelhecimento do vinho (AMERINE; OUGH, 1986). Segundo Lona (1996), a coloração amarelada dos vinhos brancos está diretamente relacionada com a região de procedência da uva, com a tecnologia de vinificação empregada, com o grau de oxidação e com o período de envelhecimento do vinho. 
Os compostos fenólicos existentes nas uvas podem ser classificados em flavonoides e nãoflavonoides. Os flavonoides são caracterizados pelos flavanois como as catequinas, epicatequeinas e epigalocatequinas e pelos flavonois como caempferol, quercetina, miricetina e antocianinas. Os compostos não-flavonoides são caracterizados pelos ácidos fenólicos, hidroxibenzoicos e hidroxicinâmicos (CABRITA; RICARDO-DA-SILVA; LAUREANO, 2003). Os ácidos fenólicos pertencentes ao grupo de compostos não-flavonoides são os principais representantes fenólicos das uvas brancas, influenciando no aroma e no gosto dos vinhos elaborados com essas cultivares (ABE et al., 2007).

Diante de toda essa diversidade de substâncias químicas componentes dos vinhos, muitos estudos tem abordado diversas metodologias de avaliação sensorial dessa bebida, visto sua alta complexidade. Das metodologias mais aplicadas, atualmente, destacam-se os métodos descritivos como a ADQ - Análise Descritiva Quantitativa e a análise de preferência de consumidores de vinhos por meio da aplicação de ferramentas estatísticas multivariadas como a Análise de Componentes Principais e o Mapa de Preferência Interno (BEHRENS, 1998).

A Análise de Componentes Principais (ACP) é uma das técnicas multivariadas mais simples e consiste em analisar um conjunto de variáveis e encontrar combinações destas variáveis para produzir componentes que não estejam correlacionados entre si na ordem de sua importância, mas que expliquem a variação dos dados. A idéia básica é reduzir o número de variáveis por meio da combinação linear de cada atributo, esperando que a variação dos dados seja explicada pelo mínimo de componentes possíveis, reduzindo, de fato, o número de variáveis a serem analisadas (MANLY, 2008).

Em função do exposto acima, o objetivo desse trabalho está em determinar algumas das principais propriedades físico-químicas de três vinhos brancos, dois vinhos de mesa e um vinho fino, de vinícolas da região noroeste do estado de São Paulo, além de caracterizar o perfil sensorial dessas bebidas por meio da aplicação da Análise de Componentes Principais.

\section{MATERIAL E MÉTODOS}

A avaliação físico-química e sensorial foi realizada com amostras de vinhos brancos de mesa adquiridos em comércios locais da cidade de São José do Rio Preto, sendo que cada um deles pertencia a uma vinícola diferente da região noroeste do estado de São Paulo. Dois vinhos brancos secos de mesa: A com 10,0\% de álcool (v/v) e B com 11,5\% de álcool (v/v); e um vinho branco fino seco $\mathrm{F}$ com $11,5 \%$ de álcool, todos os teores especificados em rótulo, foram analisados de acordo com as metodologias descritas na Tabela 1.

Além das determinações analíticas expostas na Tabela 1, a acidez fixa (ACF) foi determinada pela subtração da acidez total com a acidez volátil (IAL, 2005). As análises físico-químicas foram realizadas em triplicata e analisadas estatisticamente pelo teste não-paramétrico de Kruskal-Wallis com aplicação do teste de comparação múltipla de Dunn a 5\% de significância.

A análise sensorial dos vinhos brancos foi realizada com estudantes, professores e colaboradores do Instituto de Biociências, Letras e Ciências Exatas da Universidade Estadual Paulista 
"Júlio de Mesquita Filho" e consistiu, basicamente, de duas etapas: a primeira etapa caracterizou-se pela aplicação de testes triangulares com o objetivo de selecionar os provadores para a avaliação comparativa das amostras através da identificação de uma amostra diferente frente outras duas amostras iguais. Após a aplicação do teste triangular, procedeu-se com a segunda etapa: a análise comparativa das amostras de forma monádica, ou seja, apresentando as amostras uma de cada vez, sendo que cada um dos provadores avaliava a referida amostra utilizando uma escala numérica estruturada com 11 pontos, sendo 0 o pior conceito e 10 o melhor conceito. Os atributos avaliados foram: acidez (ACD), corpo (COP), doçura (DOC), adstringência (ADS), teor alcoólico (ALC), cor (COR) e odor (ODR). Além disso, os provadores foram caracterizados quanto à preferência das amostras e à frequência de consumo da bebida. As análises sensoriais foram realizadas no período da tarde, entre 14 e 17 horas, no Laboratório de Análise Sensorial do Instituto.

Tabela 1: Materiais utilizados e metodologias empregadas para as determinações analíticas.

\begin{tabular}{lcc}
\hline Determinação analítica & Materiais & Metodologia \\
\hline Acidez total (ACT) & $\begin{array}{c}\text { pHmetro e aparelhagem para } \\
\text { titulometria }\end{array}$ & BRASIL (1986); IAL (2005) \\
Acidez volátil (ACV) & $\begin{array}{c}\text { Destilador Tecnal TE0363 } \\
\text { Cadinhos e banho termostático a }\end{array}$ & AOAC (1992); IAL (2005) \\
Extrato Seco (EXT) & $100^{\circ} \mathrm{C}$ & \\
Fenólicos totais (FEN) & $\begin{array}{c}\text { Espectrofotômetro de absorbância } \\
\text { Quimis - Q798U }\end{array}$ & FOLIN, CIOCALTEAU (1927) \\
Sulfatos (SUL) & $\begin{array}{c}\text { Tubos de ensaio e banho } \\
\text { termostático }\end{array}$ & BRASIL (1986); IAL (2005) \\
Açúcar redutor (ACR) & $\begin{array}{c}\text { Determinador de açúcares redutores } \\
\text { (Redutec) Tecnal TE0861 }\end{array}$ & AOAC (1992) \\
Álcool (ALC) & $\begin{array}{c}\text { Destilador de arraste a vapor e } \\
\text { banho termostático a 60C }\end{array}$ & JOSLYN (1950); MEYER, \\
LEYGUE-ALBA (1991)
\end{tabular}

\section{RESULTADOS E DISCUSSÃO}

\section{Determinações analíticas}

Os resultados das determinações analíticas dos vinhos brancos avaliados no estudo encontram-se na Tabela 2. 
Tabela 2: Medianas (amplitudes) das determinações analíticas dos vinhos brancos avaliados no estudo. Valor $\mathbf{P}$ referente ao teste de Kruskal-Wallis.

\begin{tabular}{lcccc}
\hline Determinações & Vinho A & Vinho B & Vinho F & Valor P \\
\hline ACT (mEq/L) & $93,53^{\mathrm{B}}(4,62)$ & $121,82^{\mathrm{A}}(2,02)$ & $106,51^{\mathrm{AB}}(2,30)$ & $\mathbf{0 , 0 2 7}$ \\
ACV (mEq/L) & $12,64(3,04)$ & $17,63(4,16)$ & $13,64(3,30)$ & 0,099 \\
ACF (mEq/L) & $80,89^{\mathrm{B}}(7,20)$ & $104,18^{\mathrm{A}}(6,12)$ & $92,87^{\mathrm{AB}}(3,98)$ & $\mathbf{0 , 0 2 7}$ \\
EXT (g/L) & $21,50^{\mathrm{B}}(4,36)$ & $29,17^{\mathrm{AB}}(3,79)$ & $45,17^{\mathrm{A}}(0,58)$ & $\mathbf{0 , 0 2 7}$ \\
SUL (g/L) & entre 0,7 e 1 & menor que 0,7 & menor que 0,7 & - \\
FEN (g/L) & $0,367^{\mathrm{A}}(0,008)$ & $0,234^{\mathrm{AB}}(0,030)$ & $0,178^{\mathrm{B}}(0,006)$ & $\mathbf{0 , 0 2 7}$ \\
ACR (g/L) & $1,07^{\mathrm{B}}(0,01)$ & $1,38^{\mathrm{AB}}(0,04)$ & $4,83^{\mathrm{A}}(0,08)$ & $\mathbf{0 , 0 2 7}$ \\
ALC (\% v/v) & $9,75(0,90)$ & $10,35(0,82)$ & $10,70(0,64)$ & 0,079 \\
\hline dianas seguidas por letras distintas na mesma linha diferem entre si pelo teste de Dunn a $5 \%$ de \\
ificância. ACT: acidez total, ACV: acidez volátil, ACF: acidez fixa, EXT: extrato seco, SUL: sulfatos, FEN:
\end{tabular}

Os resultados apresentados na Tabela 2 mostram a existência de diferenças estatisticamente significativas entre as amostras avaliadas relativas às seguintes determinações analíticas: acidez total (ACT), acidez fixa (ACF), extrato seco total (EXT), teor de fenólicos totais (FEN) e teor de açúcares redutores (ACR), todas elas com valor $P$ inferior ao nível de significância adotado $(P=0,027)$. $O$ teste de comparação múltipla de Dunn mostrou que as discrepâncias relativas às determinações de acidez (total e fixa) foram observadas entre as amostras dos vinhos de mesa, sendo que a amostra de vinho fino não apresentou discrepâncias em relação aos vinhos brancos de mesa. Entretanto, para as demais determinações que resultaram em significância estatística, verificou-se que a diferença está entre a amostra de vinho de mesa A e a amostra de vinho fino.

Todos os índices de acidez determinados apresentaram-se de acordo com os limites preconizados pela legislação brasileira para vinhos, ou seja, entre $55 \mathrm{mEq} / \mathrm{L}$ e $130 \mathrm{mEq} / \mathrm{L}$ (BRASIL, 1999). Apesar disso, a divergência observada entre os vinhos de mesa para essas determinações pode ser pressuposta pela diferença no processo de vinificação e pela utilização de diferentes espécies de uvas para a elaboração dos vinhos (JACKSON, 2000). Como os vinhos avaliados não eram varietais, ou seja, não foram elaborados somente com um tipo de cultivar, a formação dos ácidos característicos da acidez fixa, como o ácido tartárico, málico, succínico, entre outros, foi diferenciada devido às diferentes espécies de uvas envolvidas no processo de vinificação. Além disso, como o processo de vinificação varia de vinícola para vinícola, tal fato se tornou influência direta na produção desses ácidos, promovendo a discordância observada nos resultados.

Os resultados dos índices de extrato seco foram esperados, visto que os vinhos finos apresentaram-se mais encorpados que os vinhos de mesa. Segundo Zoecklein et al. (1994), o vinho seco com teor de extrato seco inferior a $20 \mathrm{~g} / \mathrm{L}$ apresenta-se leve ao paladar; em contrapartida, o vinho seco com 30g/L ou mais é considerado como encorpado. Nesse contexto, os vinhos de mesa 
apresentaram teor de extrato seco inferior a $30 \mathrm{~g} / \mathrm{L}$, entretanto o vinho fino apresentou teor de extrato seco superior a $30 \mathrm{~g} / \mathrm{L}$, pressupondo seu elevado corpo. Sugeriu-se que tal constatação esteja vinculada à maior solubilização das substâncias sólidas da uva na etapa de maceração que, para os vinhos finos, é mais prolongada quando comparada aos vinhos de mesa (SILVA et al., 1999). Além disso, o período de estabilização dos vinhos também pode ser considerado como um fator preponderante, visto que os vinhos finos apresentam maior tempo de estabilização quando comparados aos vinhos de mesa (GUERRA; ZANUS, 2004).

O teor de fenólicos totais, de acordo com os resultados da Tabela 2, mostrou diferenças entre o vinho de mesa A e o vinho fino, visto que o vinho de mesa apresentou maior teor frente ao vinho fino. Benassi e Cecchi (2000) mostraram que a proporção de catequina e ácidos fenólicos diferenciaram-se em amostras de vinhos brancos da cultivar Riesling Itálico devido ao estágio diferenciado de maturação da uva. Nesse contexto, os teores de catequina aumentariam durante o amadurecimento, decrescendo até a colheita e para outros compostos fenólicos diminuiriam continuamente até a maturação (LEE; JAMORSKY, 1989; SIMÓN; ESTRELLA, 1993). Além disso, processos de clarificação dos vinhos envolvendo compostos como bentonite e gelatina diminuem o teor de ácidos fenólicos enquanto que o uso de polivinilpolipirrolidona diminui o teor de catequina (BONAGA; PALLOTTA; SYRGHI, 1990). Nesse caso, pressupõe-se que o menor índice de fenólicos do vinho fino pode ser explicado pelo estágio diferenciado de maturação das cultivares e pela utilização de substâncias clarificantes. Nesse contexto, pressupõe-se que a vinícola produtora do vinho de mesa A não utilizou compostos clarificantes, evidenciando menor complexação dos compostos fenólicos e, por conseguinte, maior teor de fenólicos totais em relação ao vinho fino.

Os teores de açúcares redutores diferenciaram-se de foram significativa quando o vinho de mesa A foi comparado ao vinho fino, embora todas as amostras apresentaram teores de açúcares redutores abaixo de $5 \mathrm{~g} / \mathrm{L}$, sendo classificadas como vinhos secos (BRASIL, 1999). Como não se tratam de varietais, o teor de açúcares redutores superior do vinho fino pode estar vinculado às espécies vinificadas, visto que cada cultivar apresenta em sua composição uma determinada quantidade de açúcares não-fermentescíveis da classe das pentoses, sendo as principais a arabinose e a xilose (BLASI, 2004).

Todas as amostras apresentaram-se de acordo com a legislação em relação ao teor alcoólico, ou seja, apresentaram teores entre 8,6 e $14^{\circ} \mathrm{GL}$, sendo classificadas como vinhos de mesa (amostras $\mathrm{A}$ e B) e vinho fino (amostra F). Entretanto, não apresentaram a quantidade de álcool especificada no rótulo. Não foi possível observar diferenças significativas entre os teores alcoólicos das amostras avaliadas no estudo, pressupondo que as uvas utilizadas, no início da vinificação, apresentaram-se similares quanto ao teor de sólidos solúveis, ou as amostras apresentaram semelhante correção do teor alcoólico pela inserção direta de sacarose no mosto (chaptalização).

\section{Análise sensorial}

A aplicação do teste triangular foi realizada com 35 provadores, sendo que desse total, 11 provadores conseguiram discriminar a amostra diferente, sendo esses os selecionados para a análise comparativa das amostras. Em relação à caracterização desses provadores foi possível constatar que 
$54,5 \%$ deles às vezes consomem vinho; $36,4 \%$ consomem frequentemente e $9,1 \%$ raramente consomem vinhos brancos. A preferência de consumo também foi questionada e os resultados mostraram que os vinhos de mesa A e B, com $36,4 \%$ cada um, foram os preferidos em relação ao vinho fino com $27,3 \%$ de preferência. Além disso, o vinho fino apresentou $54,5 \%$ de negativação quanto à preferência. A Tabela 3 mostra a média e o desvio padrão dos parâmetros sensoriais avaliados para cada uma das amostras de vinho branco avaliadas no estudo.

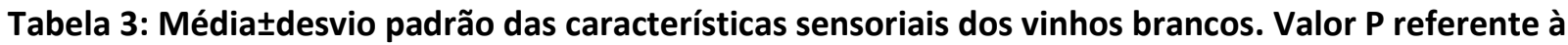
Análise de Variância.

\begin{tabular}{lcccc}
\hline Atributos & Vinho A & Vinho B & Vinho F & Valor P \\
\hline Acidez (ACD) & $6,45 \pm 2,16$ & $7,36 \pm 1,80$ & $6,90 \pm 2,62$ & 0,636 \\
Corpo (COP) & $6,90 \pm 2,73$ & $6,54 \pm 2,91$ & $6,09 \pm 2,66$ & 0,788 \\
Doçura (DOC) & $6,22 \pm 2,33$ & $4,68 \pm 2,51$ & $6,36 \pm 2,42$ & 0,212 \\
Adstringência (ADS) & $5,50 \pm 2,92$ & $6,45 \pm 2,38$ & $6,27 \pm 2,64$ & 0,674 \\
Álcool (ALC) & $6,36 \pm 1,80$ & $7,13 \pm 2,00$ & $6,72 \pm 2,45$ & 0,839 \\
Cor (COR) & $7,54 \pm 2,69$ & $6,81 \pm 2,56$ & $7,81 \pm 2,52$ & 0,650 \\
Odor (ODR) & $6,90 \pm 2,66$ & $6,54 \pm 2,77$ & $7,31 \pm 2,34$ & 0,786 \\
\hline
\end{tabular}

De acordo com os resultados da Tabela 3 foi possível constatar a ausência de diferenças estatisticamente significativas entre as amostras quando comparadas em relação a cada um dos atributos sensoriais, visto que todos os valores $\mathrm{P}$ resultantes foram superiores ao nível de significância adotado. Desse modo, partiu-se para a aplicação da análise multivariada dos dados sensoriais por meio da aplicação da Análise de Componentes Principais. A Figura 1 mostra a contribuição de cada componente relativa à variação total dos dados sensoriais com base na matriz de covariâncias.

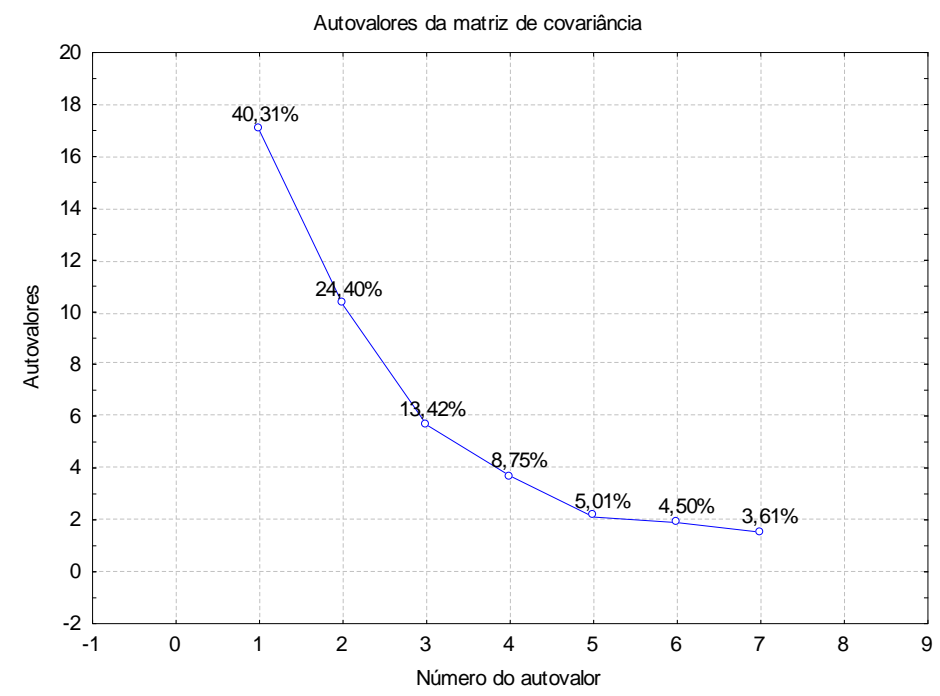

Figura 1: Percentuais correspondentes à variação total dos dados para cada componente extraído. 
A partir da Figura 1 é possível verificar que os primeiros dois componentes são responsáveis por $64,71 \%$ da variação da distribuição dos dados, sendo o componente 1 responsável por $40,31 \%$ da carga de variação e o componente 2 responsável por $24,40 \%$ da variação. A Tabela 4 mostra as cargas fatoriais dos dois componentes selecionados para o estudo dos atributos sensoriais.

Tabela 4: Cargas fatoriais dos atributos para os dois componentes extraídos de acordo com a rotação Varimax normalizada.

\begin{tabular}{lcc}
\hline Parâmetros & Componente 1 & Componente 2 \\
\hline Acidez (ACD) & 0,144741 & $-0,015738$ \\
Corpo (COP) & $\mathbf{0 , 8 6 2 6 0 4}$ & 0,001512 \\
Doçura (DOC) & 0,264866 & 0,163522 \\
Adstringência (ADS) & 0,272477 & $-0,141266$ \\
Álcool (ALC) & 0,075400 & 0,132198 \\
Cor (COR) & $-0,000723$ & $\mathbf{0 , 9 3 6 5 8 3}$ \\
Odor (ODR) & 0,079012 & 0,286287 \\
\hline
\end{tabular}

De acordo com os resultados das cargas fatoriais da Tabela 4 foi possível observar que o atributo corpo foi o mais significativo para o componente 1 e o atributo cor explicou de forma mais significativa a variação do componente 2 . A Figura 2 mostra a distribuição dos escores de cada um dos onze provadores selecionados para a avaliação das amostras em relação aos atributos sensoriais, representados pelos seus respectivos autovetores. As avaliações de cada um dos provadores estão representadas pelas letras das amostras (A, B ou F) seguidas de um número representado pelo provador (de 1 a 11).

A Figura 2 permitiu observar que os provadores 1, 3 e 7 apresentaram maior discrepância em relação aos outros provadores. $\mathrm{O}$ fato de esses provadores terem sido aprovados no teste triangular não está vinculado ao fato de eles avaliarem as amostras em consonância com os outros provadores, já que não se trata de uma análise sensorial descritiva quantitativa que exige treinamento dos provadores. Nesse contexto, com o objetivo de melhorar a discussão dos resultados da análise sensorial, esses provadores que apresentaram avaliações discrepantes ao grupo foram retirados da análise. A Figura 3 mostra a distribuição dos dados das avaliações das amostras, excluindo os provadores 1,3 e 7. 


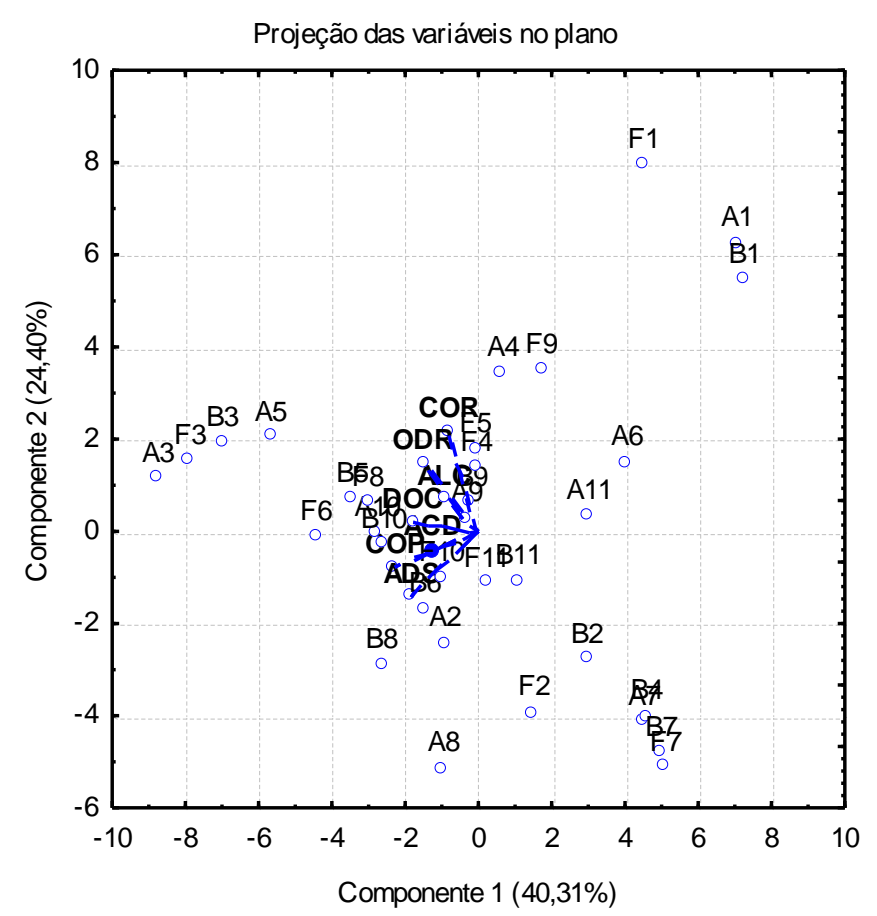

Figura 2: Distribuição de cada uma das avaliações dos provadores em relação às amostras de vinho branco.

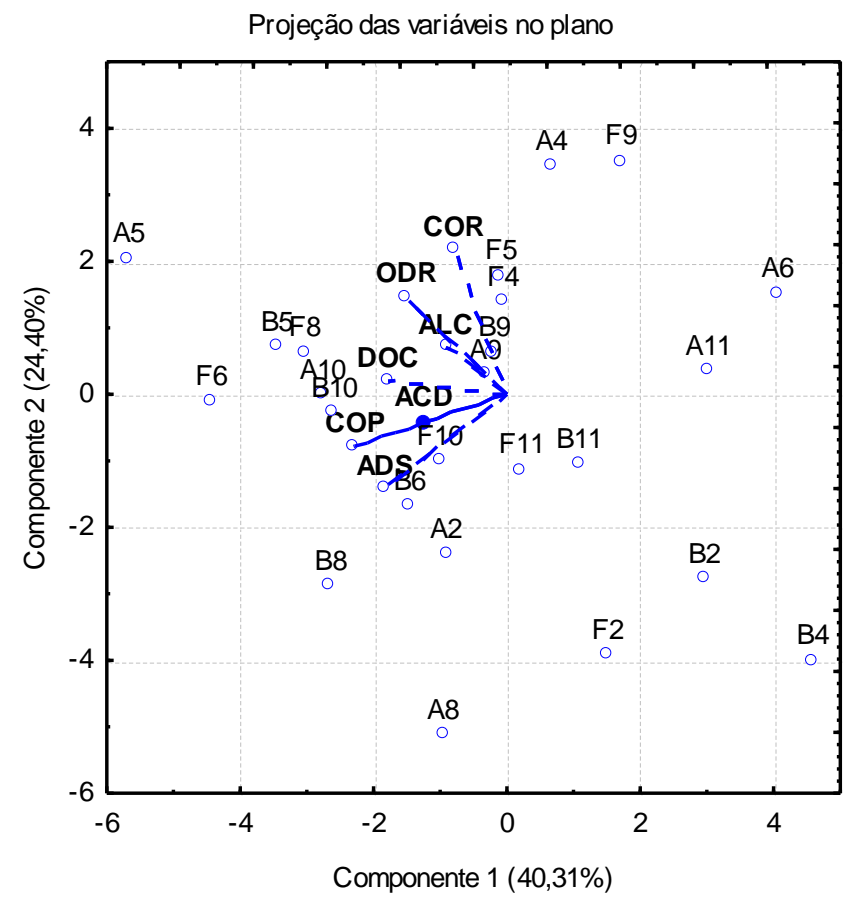

Figura 3: Distribuição de cada uma das avaliações dos provadores em relação às amostras de vinho branco, excluindo os provadores 1,3 e 7.

O gráfico da Figura 3 mostrou que, em relação ao componente 1, as avaliações de 3 provadores da amostra do vinho de mesa B e de dois provadores da amostra do vinho fino apresentaram-se mais próximas ao vetor do atributo corpo em relação às avaliações da amostra do 
vinho de mesa A. Esse resultado está de acordo com os parâmetros físico-químicos encontrados para o extrato seco que, sob o ponto de vista sensorial, está relacionado ao corpo e estrutura da bebida (RIZZON; MIELE, 1996).

Em relação ao componente 2 verificou-se que a proximidade das avaliações relativas à amostra de vinho fino ao vetor do atributo cor é maior em relação às amostras de vinhos de mesa. Além disso, as amostras de vinhos de mesa apresentaram-se mais distantes do vetor referente a esse atributo, mostrando que a cor do vinho fino apresentou-se mais atrativa aos provadores em relação à cor dos vinhos de mesa. Nesse contexto, pressupõe-se que a maior aceitação da cor do vinho fino esteja vinculada ao tempo de envelhecimento que esse tipo de vinho é submetido, etapa não realizada, muitas vezes, nos vinhos de mesa de algumas vinícolas (LONA, 1996).

Outro fato importante a ser considerado foi vinculado à localização de muitos pontos referentes às amostras A e B contrários às direções dos autovetores dos atributos doçura, acidez, teor alcoólico e corpo, reiterando os resultados das determinações físico-químicas. O vinho fino apresentou maior valor para extrato seco, teor de açúcar redutor e teor alcoólico, apresentando o segundo maior valor para acidez. Assim, vincula-se as determinações físico-químicas aos atributos sensoriais como evidenciado no estudo de Behrens (1998).

\section{CONCLUSÕES}

Este estudo trouxe resultados sobre a caracterização físico-química de três vinhos brancos da região noroeste do estado de São Paulo, elucidando aspectos sobre o perfil sensorial dessas bebidas. Apesar dos resultados sensoriais não terem apresentado diferenças estatisticamente significativas, a Análise de Componentes Principais mostrou que os atributos sensoriais vincularam-se às propriedades físico-químicas determinadas, sendo o corpo relacionado com o extrato seco total dos vinhos e o atributo cor com o teor de fenólicos totais aliado ao envelhecimento do vinho fino, etapa não aplicada aos vinhos de mesa.

Além disso, todos os vinhos apresentaram perfil físico-químico de acordo com os parâmetros preconizados pela legislação brasileira, sendo um fator importante para caracterizar a qualidade do vinho e, consequentemente, influenciar na escolha do consumidor. É importante salientar a relevância do estudo das relações entre as determinações físico-químicas e os atributos sensoriais, visto que qualquer alteração no perfil sensorial dos vinhos, após as etapas de vinificação, pode ser explicada por algum parâmetro físico-químico alterado em relação aos limites recomendados pela legislação. 


\section{REFERÊNCIAS BIBLIOGRÁFICAS}

1. ABE, L.T.; DA MOTA, R.V.; LAJOLO, F.M.; GENOVESE, M.I. Compostos fenólicos e capacidade antioxidante de cultivares de uvas Vitis labrusca L. e Vitis vinifera L. Ciência e Tecnologia de Alimentos, Campinas, v.27, n.2, 2007.

2. AMARANTE, J. O. A. A. Vinhos: do Brasil e do mundo, para conhecer e beber, São Paulo: Summus Editorial, 1983. 157p.

3. AMERINE, M. A.; OUGH, C. S. Wine and must analysis. 2. ed. New York: John Wiley \& Sons, 1986. 377 p.

4. AMERINE, M.A.; ROESSLER, E.B. Wines - Their sensory evaluation. San Francisco:W.H. Freeman and Company, 1983, 432p.

5. AOAC. Association of Official Agricultural Chemists. Official methods of analysis of the AOAC International. Washington, 1992, 1141p.

6. BARNABÉ, D. Produção de vinho de uvas dos cultivares Niágara Rosada e Bordô: análises físico-químicas, sensorial e recuperação de etanol a partir do bagaço. 2006. 106f. Tese (Doutorado em Agronomia) - Faculdade de Ciências Agronômicas, Universidade Estadual Paulista Júlio de Mesquita Filho. Botucatu, 2006.

7. BEHRENS, J.H. Avaliação do perfil sensorial e aceitação de vinhos brancos varietais Riesling, Gewürztraminer e Chardonnay produzidos no Brasil. 1998. 185p. Dissertação (Mestrado em Ciências da Nutrição) - Faculdade de Engenharia de Alimentos, Universidade Estadual de Campinas, Campinas, 1998.

8. BENASSI, M.T.; CECCHI, H.M. Caracterização de vinhos Riesling Itálico nacionais quanto aos ácidos carboxílicos e a alguns compostos fenólicos. Alimentos e Nutrição, São Paulo, v.11, 2000.

9. BLASI, T.C. Análise do consumo e constituintes químicos de vinhos produzidos na quarta colônia de imigração italiana do Rio Grande do Sul e sua relação com as frações lipídicas sanguíneas. 2004. 76p. Dissertação (Mestrado em Ciência e Tecnologia de Alimentos) Centro de Ciências Rurais, Universidade Federal de Santa Maria, Santa Maria, 2004.

10. BONAGA, G.; PALLOTTA, U.; SYRGHI, K. Influenza delle sostanze polifenoliche sulla qualità dei vini bianchi. Parte prima. Vini d'Itália, v.4, p.13-30, 1990.

11. BRASIL. Lei $\mathrm{n}$. 10970 de 16 de novembro de 2004 . Altera dispositivos da Lei $\mathrm{n}$. 7678 de 8 de novembro de 1988, que dispõe sobre a produção, circulação e comercialização do vinho e derivados de uva e do vinho, e dá outras providências. DOU: Diário Oficial da União, Brasília, DF, 2004.

12. BRASIL. Padrões de Identidade e Qualidade - Vinho, Derivados da Uva e do Vinho. Brasília, DF: Coordenação de Inspeção Vegetal e Serviço de Inspeção Vegetal, 1999, 25p. 
13. BRASIL. Portaria n. 76 de 27 de novembro de 1986. Aprova os métodos analíticos que passam a constituir padrões oficiais para análise de bebidas e vinagres estabelecidos pelo Decreto n. 73267 de 06 de dezembro de 1973. DOU: Diário Oficial da União, Brasília, DF, 1986, seção 1, p. 18152-18173.

14. CABRITA, M. J.; RICARDO-DA-SILVA, J.; LAUREANO, O. Os compostos polifenólicos das uvas e dos vinhos. In: I SEMINÁRIO INTERNACIONAL DE VITIVINICULTURA. Anais...Ensenada, México, 2003.

15. CAMARGO, U.A. Técnicas de produção vitícola com ciclos sucessivos em condições tropicais. In: WORKSHOP INTERNACIONAL DE PESQUISA, 1., 2004, Petrolina e Recife. Anais... Petrolina e Recife: 2004, 11p. Disponível em: <http://www.cnpuv.embrapa.br/publica/anais/wip2004/85.pdf >. Acesso em: 08 maio 2011.

16. FOLIN, O.; CIOCALTEAU, V. On tyrosine on triptophane determinations in proteins. Journal of Biololgy and Chemistry, v. 73, n. 2, p. 627-651. 1927.

17. GUERRA, C.C. Influência de parâmetros enológicos da maceração na vinificação em tinto sobre a evolução da cor e a qualidade do vinho. In: CONGRESSO BRASILEIRO DE VITICULTURA E ENOLOGIA - INFLUÊNCIA DA TECNOLOGIA VITÍCOLA E VINÍCOLA NA COR DOS VINHOS, n. 10, 2003, Bento Gonçalves. Anais..., Bento Gonçalves: 2003.

18. GUERRA, C.C.; ZANUS, M.C. Características analíticas e sensoriais de vinhos produzidos no Vale Submédio São Francisco. In: Workshop Internacional de Pesquisa - A produção de vinhos em regiões tropicias, n.1, 2004, Petrolina e Recife. Anais..., Recife: 2004.

19. INSTITUTO ADOLFO LUTZ. Normas analíticas do Instituto Adolfo Lutz. v. 1: Métodos químicos e físicos para análise de alimentos. 4. ed. São Paulo: IMESP, 2005. 1020p.

20. JACKSON, R. S. Wine science: Principles, practice and perception. 2.ed. San Diego, C.A: Elsevier Academic Press, 2000. 647p.

21. JOSLYN, M.A. Methods in Food Analysis. New York: Academic Press, 2 ed, 1950, 525p.

22. LEE, C.Y.; JAMORSKY, A.W. Major phenolic compounds in ripening white grapes. Am. J. Enol. Vitic., v.41, p.289-94, 1989.

23. LONA, A.A. Vinhos - Degustação, Elaboração e Serviço. Porto Alegre: Editora Age Ltda., 1996, 151p.

24. MANLY, B.F.J. Métodos estatísticos multivariados: uma introdução. Porto Alegre: Artmed, 2008, 229p.

25. MAZZOCHI, C. L.; IDE, G. M. Características de alguns vinhos produzidos em Santa Catarina. Agropecuária Catarinense, Florianópolis, v.7, n.3, p.17-19, 1994. 
26. MELLO, L.M.R. Tendências de consumo e perspectivas de mercado de vinhos no Brasil. EMBRAPA Uva e Vinho - CNPUV, Bento Gonçalves, 7p. 2002. Versão eletrônica. Disponível em: <http://www.cnpuv.embrapa.br/publica/artigos/tendencia.pdf $>$. Acesso em: 20 abr. 2011.

27. MEYER, C.R.; LEYGUE-ALBA, N.M.R. Manual de Métodos Analíticos Enológicos. EDUCS: Caxias do Sul, 1991. 59p.

28. OIV. Organisation Internationale de la Vigne et du Vin. Recueil des methodes internationales d'analyse des vins et des mouts. Caractéristiques chromatiques. 5 ed. v. 1. 2005.

29. RIZZON, L. A.; MIELE, A. Extrato seco total de vinhos brasileiros: comparação de métodos analíticos. Ciência Rural, Santa Maria, v. 26, n.2, p. 297-300, 1996.

30. RIZZON, L. A.; MIELE, A.; MENEGUZZO, J. Efeito da relação das fases líquida e sólida da uva na composição química e na característica sensorial do vinho Cabernet. Embrapa Uva e Vinho, Bento Gonçalves, 1999.

31. RIZZON, L.A. Sistema de produção de vinho tinto: Recebimento da uva. Sistemas de Produção - EMBRAPA Uva e Vinho - CNPUV. Bento Gonçalves, 2006. Disponível em:<http://www.cnpuv.embrapa.br/publica/sprod/VinhoTinto/recebimento.htm>.

Acesso em 28 abr. 2011.

32. ROSIER, J.P. Manual de elaboração de vinho para pequenas cantinas. 2.ed. Florianópolis: EPAGRI, 1993. 72p.

33. SILVA, T.G.; REGINA, M.A.; ROSIER, J.P.; RIZZON, L.A.; CHALFUN. N.N.J. Diagnóstico vinícola do sul de Minas Gerais - Caracterização físico-química dos vinhos. Ciência Agrotécnica, Lavras, v.23, n.3, p. 623-637, 1999.

34. SIMÓN, B.F.; ESTRELLA, T.H. Phenolic composition of white grapes (var. Airen). Changes during ripening. Food Chemistry, v.47, p.47-52, 1993.

35. ZOECKLEIN, B.W.; FUGELSANG, K.C.; GUMO, B.H.; NURY, F.S. Wine analysis and production. New York: Chapman \& Hall, 1994, 621p. 